\title{
A BANDA MARCIAL COMO DISCIPLINA ELETIVA NO ENSINO FUNDAMENTAL EM ESCOLA DE TEMPO INTEGRAL
}

\author{
Marching band as an elective discipline in \\ elementary education in full-time school
}

\author{
Banda de música como disciplina electiva en \\ la educación primaria en escuela de tiempo \\ completo
}

\author{
Aurélio Nogueira de Sousa \\ Secretaria de Estado da Educação de Goiás \\ aureliotrompete@gmail.com \\ Eliton Perpetuo Rosa Pereira \\ Instituto Federal de Goiás \\ eliton.pereira@ifg.edu.br
}

\begin{abstract}
Resumo: O objetivo desta pesquisa é apresentar elementos da educação musical desenvolvida em escola de educação básica de tempo integral no contexto das disciplinas eletivas para a segunda fase do ensino fundamental. Em termos metodológicos, ressaltamos nossa experiência tácita, desenvolvida no contexto das escolas de tempo integral de Goiânia (Goiás, Brasil), a qual se deu de modo participante e longitudinal, cuja experiência serviu para interpretarmos os dados coletados por um grupo de estudantes da licenciatura em música (Pibid IFG, 2018 e 2019) em um survey realizado com alunos, professores e gestores da escola. Os resultados, além de apresentarem as características da educação musical na segunda fase do ensino fundamental nas disciplinas eletivas, também apontam para elementos que caracterizam esse contexto na voz dos atores participantes, de modo que sustentamos uma defesa das disciplinas eletivas para o desenvolvimento de múltiplas experiências em música e como processo formativo musical dos estudantes.
\end{abstract}

Palavras-chave: Educação musical. Ensino fundamental. Disciplinas eletivas.

\begin{abstract}
The objective of this research is to present elements of music education developed in a full-time basic education school in the context of elective classes for the second phase of elementary school. In methodological terms, we emphasize our tacit experience, developed in the context of full-time schools in Goiânia (Goiás, Brazil), which took place in a participatory and longitudinal way, whose experience served to interpret the data collected by a group of undergraduate music students (Pibid IFG, 2018 and 2019) in a survey conducted with students, teachers and school managers. The results, in addition to presenting the characteristics of music education in the second phase of elementary education in elective classes, also point to elements that characterize this context in the voice of the participating actors, so that we support a defense of elective classes for the development of multiple experiences in music and as a musical training process for students.
\end{abstract}

Keywords: Musical education. Elementary school. Elective classes.

Resumen: El objetivo de esta investigación es presentar elementos de la educación musical desarrollados en una escuela de educación básica de tiempo completo en el contexto de cursos optativos para la segunda fase de la escuela primaria. En términos metodológicos, destacamos nuestra experiencia tácita, desarrollada en el contexto de las escuelas de tiempo completo en Goiânia (Goiás, Brasil), que se desarrolló de manera participativa y longitudinal, cuya experiencia sirvió para interpretar los datos recolectados por un grupo de estudiantes universitarios de música (Pibid IFG, 2018 y 2019) en una encuesta realizada a estudiantes, docentes y directores de la escuela. Los resultados, además de presentar las características de la educación musical en la segunda fase de educación básica en clases electivas, también apuntan a elementos que caracterizan este contexto en la voz de los actores participantes, por lo que apoyamos una defensa de clases electivas para el desarrollo de múltiples experiencias en la música y como un proceso de formación musical para los estudiantes.

Palabras clave: Educación musical. Enseñanza fundamental. Clases electivas. 


\section{INTRODUÇÃO}

Esta pesquisa apresenta elementos contextuais da educação musical desenvolvida em escola de educação básica de tempo integral, especificamente no âmbito das disciplinas eletivas para a segunda fase do ensino fundamental. Damos um destaque para o impacto recebido pela banda escolar em função da ampliação do espaço para os conteúdos e experiências musicais no contexto da escola.

Consideramos que a escola de tempo integral, e toda a gama de subtemáticas que envolve essa configuração, se tornam um grande guarda-chuva para os elementos que aqui tratamos, como: educação integral, disciplinas eletivas, banda marcial, educação musical, ensino fundamental (segunda fase).

Com o objetivo principal de descrever o contexto da educação musical nas escolas de tempo integral, procuramos compreender como a banda marcial se configura entre as disciplinas eletivas, ${ }^{1}$ considerando ainda a disponibilidade de outros espaços musicais para os estudantes, e também como esses estudantes percebem e sentem o impacto dessa educação musical amplamente vivenciada nesse contexto.

Em termos metodológicos, consideramos uma observação participante realizada ao longo de mais de cinco anos de trabalho pedagógico. Assim, avaliamos que essa experiência, casada com o referencial teórico aqui apresentado, se torna suficiente para a interpretação de um questionário respondido por 162 estudantes sobre o sentido da música vivenciada na escola.

Além do contexto da escola pública de educação básica de tempo integral, ainda apresentamos os resultados da pesquisa de opinião com os estudantes, do $6^{\circ}$ ao $9^{\circ}$ anos do ensino fundamental, e procuramos compreender o perfil socioeconômico e cultural desses estudantes, como eles vivenciam a música no contexto escolar e também qual o sentido da música para suas vidas.

Verificamos que essa temática é nova no cenário da pesquisa em educação musical, considerando que Loureiro (2003) foi uma das primeiras pesquisadoras a entrar mais efetivamente em investigações sobre educação musical escolar e, ainda, tendo em conta que Del-Ben (2013) e Pires e Dalben (2013), ao realizarem um levantamento completo sobre a investigação em educação musical no Brasil, não mencionam as escolas de tempo integral, provavelmente em função da novidade e especificidade do contexto. Já os trabalhos de Penna (2011), Veber (2012), Souza (2015) e Sousa (2017) foram pioneiros ao analisar o ensino de música em escolas de tempo integral e apresentam pontos positivos em relação à ampliação do tempo da música na escola. Nesse sentido, procuramos dar a conhecer o contexto das escolas de tempo integral em Goiás, o qual consideramos singular, apresentando desafios e possibilidades de efetivação de uma educação musical pública, gratuita e ampliada - a qual compõe parte da formação integral do cidadão brasileiro.

\footnotetext{
1 Disciplinas ofertadas nas escolas de tempo integral que são escolhidas pelos estudantes, os quais são reagrupados por interesse em uma ou outra disciplina e não por idade. Algumas dessas disciplinas funcionam como oficinas.
} 


\section{METODOLOGIAS INTEGRADAS NA INVESTIGAÇÃO}

Consideramos a observação longitudinal, com base nas indicações metodológicas de Vianna (2003) sobre pesquisa de observação em educação, como direcionadora e fundamentadora de nossa experiência. Nesse sentido, a interpretação qualitativa da pesquisa de observação pôde dar luz aos dados coletados no contexto descritivo quantitativo, que, no caso deste estudo, foi realizado por meio de um survey (Walter, 2013). Assim, as diretrizes da observação longitudinal dão suporte para uma interpretação do real captado pela experiência ao longo de anos de convivência no contexto pedagógico-musical que é apresentado nos dados coletados por meio do questionário da pesquisa survey (Walter, 2013).

O survey foi aplicado com base nas indicações metodológicas de Babbie (2013) e de Freitas, Oliveira, Saccol e Moscarola (2000), os quais apresentam várias abordagens de aplicação de procedimentos de coleta de dados e também diferentes lógicas de interpretação dos dados coletados.

Nesse sentido, obtivemos 162 respostas de estudantes do ensino fundamental $\mathrm{II}^{2}$ sobre suas percepções sobre as aulas de música ministradas no contexto escolar. Apresentamos a seguir a lista de itens que compuseram o questionário:

- Idade do(a) aluno(a)

- Sexo (gênero) no RG

- Série (ano) que está cursando

- Bairro onde mora

- Escolaridade da mãe

- Profissão da mãe

- Escolaridade do pai

- Profissão do pai

- Há quanto tempo você tem aula de música na escola?

- Você costuma separar momentos para ouvir música?

- Quais os meios mais usados para ouvir música? (até 2 opções)

- Qual o gênero ou estilo de música que você gosta de ouvir? (até 2 opções)

- Como você vivencia a música na escola? (múltipla escolha)

- Qual o seu nível de satisfação com as aulas de música na escola?

- Quais as contribuições das aulas de música para a sua vida?

- Quais outras atividades artísticas você faz na escola? (múltipla escolha)

- Você faz aula de música fora da escola? Ou participa de outra atividade musical fora?

- Como você vivencia música fora da escola? (múltipla escolha)

- Vivencia-se música fora da escola, explique como é; nome do grupo, projeto ou estilo musical

- Como você avalia a sua prática musical fora da escola?

\footnotetext{
2 Ainda que haja um pequeno grupo de respondentes do ensino médio, a grande maioria (mais de $90 \%$ ) dos
} participantes pertencem à segunda fase do ensino fundamental. 
Compreendemos, ao longo do processo de contato longitudinal com o contexto e durante o tratamento preliminar com as respostas, que a interpretação dos dados deveria envolver basicamente três categorias: 1) identificação dos estudantes; 2) relações com a música; e 3) relações com a educação musical no contexto das eletivas na segunda fase da educação básica em escola de tempo integral.

\section{ESCOLAS DE TEMPO INTEGRAL NO BRASIL E A EDUCAÇÃO MUSICAL}

Antes de apresentar os resultados do survey aplicado junto aos estudantes, e sua necessária interpretação contextual, discorremos a seguir sobre o que são as escolas de tempo integral no contexto educacional brasileiro, como as escolas de tempo integral foram implementadas em Goiânia (Goiás) e, ainda, como a educação musical se configurou nesse contexto.

\section{Escolas de tempo integral e a educação integral no Brasil}

Para uma melhor compreensão da temática da educação em tempo integral no Brasil, começamos retornando à primeira metade do século XX, onde aparece inicialmente a temática da educação integral. Coelho $(2009$, p. 88) explica que na primeira metade do século XX no Brasil coexistiam movimentos, tendências e correntes com propostas politico-sociais e teórico-metodológicas diversas, que, ao discutirem temáticas ligadas à educação, defendiam a educação integral nesse contexto:

Desse grupo mesclado faziam parte, por exemplo, os católicos que, por meio de suas instituições escolares, efetivavam uma concepção de educação integral calcada em atividades intelectuais, físicas, artísticas e ético-religiosas, aliadas a uma disciplina rigorosa, aos integralistas, aos anarquistas e aos liberais, como Anísio Teixeira, que defendia e implantou instituições públicas escolares, entre as décadas de 30 e 50, em que essa concepção de educação foi praticada.

Falar de educação integral no Brasil, é falar de uma história de bravura, luta e conquistas que muitos educadores fizeram para nosso país e nosso povo. Assim, as preocupações educacionais dos anos de 1920 culminaram na elaboração do Manifesto dos Pioneiros da Educação Nova, em 1932, assinado pelos principais expoentes do meio educacional brasileiro: Fernando de Azevedo, com o apoio de Anísio Teixeira, Roquette-Pinto, Mario Casassanta, Cecília Meireles. Esses pensadores se basearam em partes dos ideários educacionais implantados em outros territórios, adaptando-os ao contexto brasileiro. Surge, portanto, o desafio e a proposta de que todos os indivíduos têm o direito à educação, cabendo à esfera pública ofertá-la de forma gratuita. 
Essa discussão vai avançar em várias propostas desenvolvidos ao longo do tempo, em vários contextos da educação brasileira, até chegarmos às questões curriculares de reorganização do tempo escolar, como defendido por Arroyo (1988). Segundo Cavaliere (2007, p. 65):

A organização social do tempo é um elemento que simultaneamente reflete e constitui as formas organizacionais mais amplas de uma dada sociedade. Dentre os meios de organização do tempo social destaca-se o tempo de escola que, sendo a mais importante referência para a vida das crianças e adolescentes, tem sido, no mundo contemporâneo, um pilar para a organização da vida em família e da sociedade em geral.

Assim, surgem os primeiros modelos do que seria educação integral que segundo Moll e Leclerc (2013) estariam presentes nas Escolas Parque e Centros Integrados de Educação Pública (Cieps), cuja estrutura educacional trabalha com a perspectiva de que todos são iguais, diferenciando somente capacidades cognitivas. É a ideia de implantação de uma democracia educacional aliada à necessidade política, pois se torna relevante o aumento no número de escolas e de alunos matriculados, o que promoveria o governo do então presidente de Getúlio Vargas. Segundo Moll e Leclerc (2013, p. 296), nesse contexto, destaca-se a figura do grande educador Anísio Teixeira:

Anísio Teixeira propunha a expansão do próprio conceito acerca da escola e da sua função social. Pensava na escola para o aprendizado. As ciências, na escola-oficina para o desenvolvimento das mais diversas habilidades, na escola das artes e da cultura, na escola dos esportes, na escola como espaço de convivência e múltiplas aprendizagens com espaços para alimentação, biblioteca e jardins.

A ampliação, expansão do tempo escolar tem sido muito questionada, debatida em vários eventos da educação, assim é preciso ter diferentes análises para compreender a educação integral e a escola em tempo integral. Há tempos, nosso sistema educacional brasileiro vem passando por transformações de caráter político, social e pedagógico. De fato, podemos ter uma visão mais ampla da escola a partir da realidade social total. Arroyo (1988, p. 4) faz uma definição da escola em tempo integral:

Um ponto inicial que deve ser ponderado: na história da educação, quando não se fala apenas em escola, mas escola de tempo integral, está se pensando em proposta de educação e formação integral. Atualmente, quando se passa a distinguir a escolarização universal da educação integral, ou quando se pensa uma escola mais abrangente, estão buscando espaços, tempos e métodos de formação integral da criança, que supostamente não são atingidos nos espaços, tempos e métodos de escolarização. 
Assim, observamos que a educação integral ou de tempo integral tem se desenvolvido ao longo dos anos, tendo por base o cunho social e as implicações e mudanças políticas. Cavaliere (2009) promove em seu artigo algumas reflexões sobre o tema da ampliação e diversificação na oferta de atividades. A autora busca provocar uma reflexão sobre o investimento dos recursos públicos em dois modelos: um modelo como escola de tempo integral e o outro como aluno em tempo integral.

No primeiro, a ênfase estaria no fortalecimento da unidade escolar, com mudanças em seu interior pela atribuição de novas tarefas, mais equipamentos e profissionais com formação diversificada, pretendendo propiciar a alunos e professores uma vivência institucional de outra ordem. No segundo, a ênfase estaria na oferta de atividades diversificadas aos alunos no turno alternativo ao da escola, fruto da articulação com instituições multisetoriais, utilizando espaços e agentes que não os da própria escola, pretendendo propiciar experiências múltiplas e não padronizadas (Cavaliere, 2009, p. 53).

Portanto, a escola de tempo integral vem fortalecer a educação básica em seu contexto geral; diferentemente, mas não contrariamente à proposta de educação integral, ela se configurou como forma de expansão de atividades complementares e na ampliação da presença do aluno no dia a dia na escola. Assim, nasceu o Programa Mais Educação, que também foi um dos precursores da concepção de educação integral no Brasil.

O Programa Mais Educação, criado pela Portaria Interministerial n. 17/2007 e regulamentado pelo Decreto n. 7.083/10, aumenta a oferta educativa nas escolas públicas por meio de atividades optativas que foram agrupadas em macrocampos, como acompanhamento pedagógico, meio ambiente, esporte e lazer, direitos humanos, cultura e artes, cultura digital, prevenção e promoção da saúde, educomunicação, educação científica e educação econômica. A Portaria Normativa Interministerial n. 17 , de 24 de abril de 2007, demonstra as considerações, as finalidades, os objetivos e característica do PME [...] (Bernado, 2020, p. 84).

Bernado e Christovão (2015) vão explicar que o Programa Mais Educação teve como objetivo contribuir para a melhoria da aprendizagem dos estudantes. Isso, por meio da ampliação da jornada escolar; favorecendo, desse modo, o alcance das metas pré-estabelecidas no Plano de Desenvolvimento da Educação (Brasil, 2007a). Por outro lado, segundo os autores, o programa também foi apresentado como uma estratégia do governo federal para a indução da educação integral nas escolas públicas em todo país.

A noção de educação integral acolhida pelo Mais Educação traz consigo a ideia de ampliação, para além do tempo escolar, também dos espaços educativos. Neste sentido, apresenta 
à sociedade uma nova concepção de gestão democrática, que convida a cidade a participar dos processos educativos, e compreende a transformação de todo seu território em escola. Assim, as instituições locais são chamadas a participar da construção de um projeto educacional que, apesar das metas pré-definidas, se apresenta ainda em aberto (Bernado; Christovão, 2015, p. 32260).

Como observamos, houve uma expansão da formação integral com projetos que contemplaram as escolas de nosso país. ${ }^{3}$ Haja vista a proposta de abertura de escolas de tempo integral a partir do Plano Nacional de Educação, que prevê até 2024 um significativo aumento desse modelo. Cavaliere (2014) mostra que, seguindo para o texto do PNE-2014, essa questão se tornou mais importante no debate educacional, especialmente pela priorização dos setores mais vulneráveis da população. Entretanto, nele a ETI (escola de tempo integral) é uma meta específica - meta 6 (composta por nove itens) - para todos os níveis da educação básica, no mesmo patamar de metas como a universalização do ensino fundamental ou a garantia de planos de carreira para todos os profissionais docentes. Ou seja, há uma evidente mudança de estatura do tema na linha que vai da LDB (Brasil, 1996) ao PNE-2014. ${ }^{4}$ Há nele a previsão de oferta, até 2024, de educação em tempo integral em, no mínimo, 50\% das escolas públicas de forma a atender pelo menos $25 \%$ de todos os alunos. Mantém-se a ênfase da educação básica como destinatária do tempo integral e também, no item 6.2, a prioridade para os setores vulneráveis da população (Brasil, 2014).

\section{Escolas de tempo integral em Goiânia e as disciplinas eletivas}

Segundo Ramos (2012), após 20 anos, o projeto da escola de tempo integral no estado de Goiás é retomado por meio da legislação educacional brasileira, e em consonância com esse projeto o estado de Goiás, em 2006, implantou uma proposta de ampliação de jornada escolar, denominada de Projeto Escola de Tempo Integral.

Inicialmente o projeto foi implantado em 38 (trinta e oito) unidades escolares que ofereciam os anos iniciais do ensino fundamental $\left(1^{\circ}\right.$ ao $5^{\circ}$ ano). Até o ano de 2010 participavam do projeto 120 (cento e vinte) escolas distribuídas pelo Estado em 36 (trinta e seis) Subsecretarias de Educação (Ramos, 2012, p. 50).

\footnotetext{
3 Penna (2011, p. 141) havia feito um estudo sobre os projetos de música nesse contexto do projeto Mais Educação. O que a autora chamou de uma análise de "atividades musicais em programas ligados à ampliação da jornada escolar".

4 EF1 - ensino fundamental I, EF2 - ensino fundamental II, EM - ensino médio (Goiás, [2020]).
} 
Segundo Sousa e Soares (2018), a educação brasileira assume essa diretriz de formação integral gradativamente, como pode ser observado na Constituição Federal (Brasil, 1988) nos art. 205 e 227, no Estatuto da Criança e do Adolescente (ECA) - Lei no 8.069 (Brasil, 1990), e na Lei de Diretrizes e Bases - Lei nº 9.394 (Brasil, 1996) em suas disposições transitórias. Outros instrumentos legais também contribuíram nesse processo, como o Plano Nacional de Educação (PNE) - Lei n¹0.179 (Brasil, 2001) e o Fundo de Manutenção e Desenvolvimento do Ensino Fundamental e de Valorização dos Profissionais da Educação (Fundeb) - Lei n ${ }^{\circ} 11.494$ (Brasil, 2007b).

A legislação brasileira, a partir da retomada democrática da década de 1980, vai ratificando a necessidade de politicas voltadas para a educação no tocante às potencialidades da ampliação do tempo de escola e confirmando a necessidade da busca de mais eficiência nos resultados escolares ou a adaptação às rotinas da vida urbana contemporânea, promovendo possiveis ressignificados educacionais dessa ampliação.

Contudo, tempo na escola não significa necessariamente qualidade no ensino; para que ele seja relevante são necessárias práticas pedagógicas que colaborem de fato para o desenvolvimento integral do educando, de forma que a gestão de tempo esteja em sintonia com as estratégias e metodologias diferenciadas que fomentem o ato de aprender. Neste sentido, torna-se necessário abordar a questão do tempo de escola de forma a ir além da tentativa de resolver os déficits da escola pública brasileira. Atualmente, no site oficial da Secretária de Estado da Educação de Goiás (Goiás, [2020]) constam no quadro geral das ETIs 139 escolas em todo o estado de Goiás do ensino fundamental (EF1, EF2) e do ensino médio (EM) (Lourenço, 2015).

No que diz respeito à questão curricular, Sousa e Soares (2018) explicam que a Secretaria de Estado de Educação de Goiás, por meio da Superintendência de Ensino Fundamental - Gerência de Educação Integral, é decisiva na construção da identidade, utilizando o Núcleo Diversificado na Matriz Curricular, visto que a unidade escolar em sua prática deve dialogar com tais proposições. Assim, no contexto da educação estadual em Goiás, cabe à coordenação pedagógica, coordenação da base diversificada e professores proporcionarem discussões significativas aos estudantes, a fim de despertar a curiosidade e o aprofundamento de temáticas pedagógicas, articulando-as com os demais componentes curriculares e favorecendo um espaço diversificado para análises, estudos, intervenções, produções, criatividade, atitude interdisciplinar, construção do conhecimento e enriquecimento do currículo individual e da unidade escolar.

Lourenço (2015) vai explicar que nessas discussões locais surgem as disciplinas eletivas, as quais devem ser desenvolvidas sob a forma de projetos interdisciplinares, de modo que contribuam com o enriquecimento dos conteúdos desenvolvidos no Núcleo Básico Comum. Sousa e Soares (2018) explicam que os projetos precisam ser pensados levando em consideração a valorização da cultura local, as habilidades dos professores, as necessidades de aprendizagem, e precisam proporcionar o desenvolvimento das competências socioemocionais. Para a seleção dos temas, é importante, também, que 
sejam observados os materiais e os espaços pedagógicos disponiveis nas unidades escolares. Por conseguinte, de acordo com Lourenço (2015) é imprescindivel que o currículo das eletivas seja desenvolvido de forma integrada e contextualizada, considerando a interdisciplinaridade enquanto perspectiva metodológica para buscar a relação entre os temas explorados, respeitando as especificidades das distintas áreas de conhecimento. Dessa forma, são ofertados semestralmente nas unidades escolares de tempo integral projetos interdisciplinares criados pelos professores, os quais passam por um processo criterioso de elaboração e validação e oportunizam aos estudantes a escolha das temáticas em que desejam participar.

Conforme o Projeto de Escola de Tempo Integral da Rede Estadual de Ensino, a concepção de ampliação do tempo escolar implica, necessariamente, considerar três pressupostos educativos necessários à formação plena do ser humano: a educação para democracia, a participação do aluno como prática da cidadania e a escola e a comunidade como espaços educativos de movimento, arte, cultura, aperfeiçoamento e lazer, pressupostos que partem do fundamento legal de que o ser educando é um sujeito de direitos [...] (Ramos, 2012, p. 52).

Assim, uma grande parte das escolas de tempo integral, situadas em Goiânia, possui em seus quadros eletivos: a língua portuguesa, a matemática, a horta, o esporte e as artes. Nas eletivas de artes temos dança, teatro, violão, teclado, canto coral e banda marcial e musical (trompete, trombone, tuba, trompa, eufônio, clarineta, saxofone, flauta, percussão rudimentar, percussão popular e linha de frente), e também ensino de cordas (violino, violoncelo, viola clássica e contrabaixo acústico) e teclado. As eletivas se constituem em disciplinas optativas obrigatórias no currículo da escola de tempo integral, onde os jovens têm acesso à formação em todas as áreas de conhecimento do currículo do ensino fundamental II, disponibilizado em sua estrutura curricular (Sousa; Soares, 2018), sendo ofertadas em escolas de ensino fundamental I e II quatro vezes por semana, e em escolas que possuem ensino fundamental II e ensino médio duas vezes na semana.

\section{A educação musical no contexto das disciplinas eletivas nas ETIs em Goiás}

As disciplinas eletivas ocupam um lugar central na proposta pedagógica da educação integral em Goiás no que tange à diversificação das experiências, considerando que os professores tenham condições de desenvolvê-las por meio de formações continuadas, grupos de estudos focais ou momentos formativos que oportunizam ampliar o intercâmbio de conhecimentos entre membros das unidades escolares. Observamos, no contexto de nossa unidade escolar (Cepi Ismael Silva de Jesus), que os docentes tiveram a oportunidade de discutir conceitos e práticas diferenciadas de educação integral de forma sistematizada e reflexiva, propondo intervenções pontuais ao projeto político-pedagógico, ao calendário e às demandas da unidade escolar. 
Assim, segundo Sousa e Soares (2018), vale ressaltar ainda que, quanto maior o tempo na escola, maior a probabilidade de desenvolvimento integral e integrado dos educandos, pois com o assessoramento pedagógico, terão a oportunidade de desenvolver aspectos cognitivos e sociais, consequentemente ampliando as competências em trabalhos coletivos, de forma que a escola busca desempenhar seu principal papel de preparo para a vida em sociedade e para o trabalho, fazendo jus a uma educação cidadã. Portanto, o trabalho educativo realizado nas disciplinas eletivas, considerando a interdisciplinaridade enquanto eixo metodológico para buscar a relação entre os temas explorados, se efetiva na formação dos estudantes, mas sem desprezar as especificidades das distintas áreas de conhecimento. A Resolução n 4/2010 - CNE rege que

a interdisciplinaridade e a contextualização devem assegurar a transversalidade do conhecimento de diferentes disciplinas e eixos temáticos, perpassando todo o currículo e propiciando a interlocução entre os saberes e os diferentes campos do conhecimento (Brasil, 2010, § $2^{\circ}$ ).

É nesse contexto das escolas de tempo integral que destacamos o trabalho da banda marcial nas disciplinas eletivas. Sousa e Soares (2018) descrevem como se dá o processo de implementação e participação da banda como eletiva optativa no componente curricular de uma escola de período integral da região noroeste de Goiânia. Os autores mencionam que a formação da escola de tempo integral preconiza a relevância de o aluno se assumir como copartícipe do processo ensino-aprendizagem; isso significa dizer que o aluno deve ser o centro dos processos de aquisição do conhecimento escolar. Assim, o estudante escolhe a eletiva que deseja fazer e ao optar pela eletiva da banda é inserido em uma proposta metodológica de ensino coletivo. Nesse contexto, a utilização da banda como ambiente de musicalização e ferramenta do ensino-aprendizagem da música é uma alternativa para a escola. Entretanto, o ensino da música por meio da banda ainda não conseguiu estabelecer material didático para congregar os conteúdos específicos da área.

Atualmente, no Brasil, existem métodos didáticos para as bandas de música, diferentemente de outras disciplinas do currículo escolar, que utilizam livros didáticos nas diversas áreas como forma de estabelecer um programa de conteúdo. Nas bandas escolares, situadas nas escolas de tempo integral, é possivel trabalhar com os métodos de ensino coletivo brasileiros e também norte-americanos e europeus. Isso ocorre por meio de estruturação e sistematização do ensino de música que se assenta em planejamentos quinzenais, avaliações internas e externas, reuniões pedagógicas e reuniões com pais de alunos. Para que isso ocorra de forma eficiente é importante e necessária a utilização de um material didático-pedagógico que possa apoiar e orientar as aulas de forma uniforme.

A utilização do material didático pode ser então importante na medida em que este possibilite aos professores de banda uma reflexão do seu próprio percurso de aprendizagem, podendo ainda gerar novas e diversificadas 
respostas para diferentes problemas de ensino-aprendizagem no âmbito da metodologia musical coletiva. Desse modo, a proposição de métodos brasileiros para banda tem sido válida no intuito de contribuir com a existência de novos materiais didáticos no referido assunto. De fato, a banda presente como uma eletiva optativa da escola de período em tempo integral propõe que cada professor tenha seu quantitativo de alunos por instrumento, com 20 a 25 alunos por eletiva. Para a realidade da banda marcial escolar isso foi um grande avanço para o seu fortalecimento e sua sobrevida dentro da escola. Como eletiva obrigatória no currículo a banda tem espaço garantido e com grande quantitativo de alunos participando (Sousa; Soares, 2018).

Se compararmos com as bandas que não estão inseridas em escola de período integral, estas não se configuram como disciplinas curriculares, mas como projetos de extensão, uma vez que o aluno participa por espontânea vontade, mas em horário extra, diferentemente das ETIs onde a banda está vinculada às eletivas do currículo escolar do sistema de ensino integral. Assim, o estado de Goiás é pioneiro nessa proposta da banda marcial escolar nas ETIs, que se configura em um dos grandes avanços para a educação musical no estado.

A seguir apresentamos fotografias emblemáticas do contexto da banda marcial do Cepi Ismael Silva de Jesus.

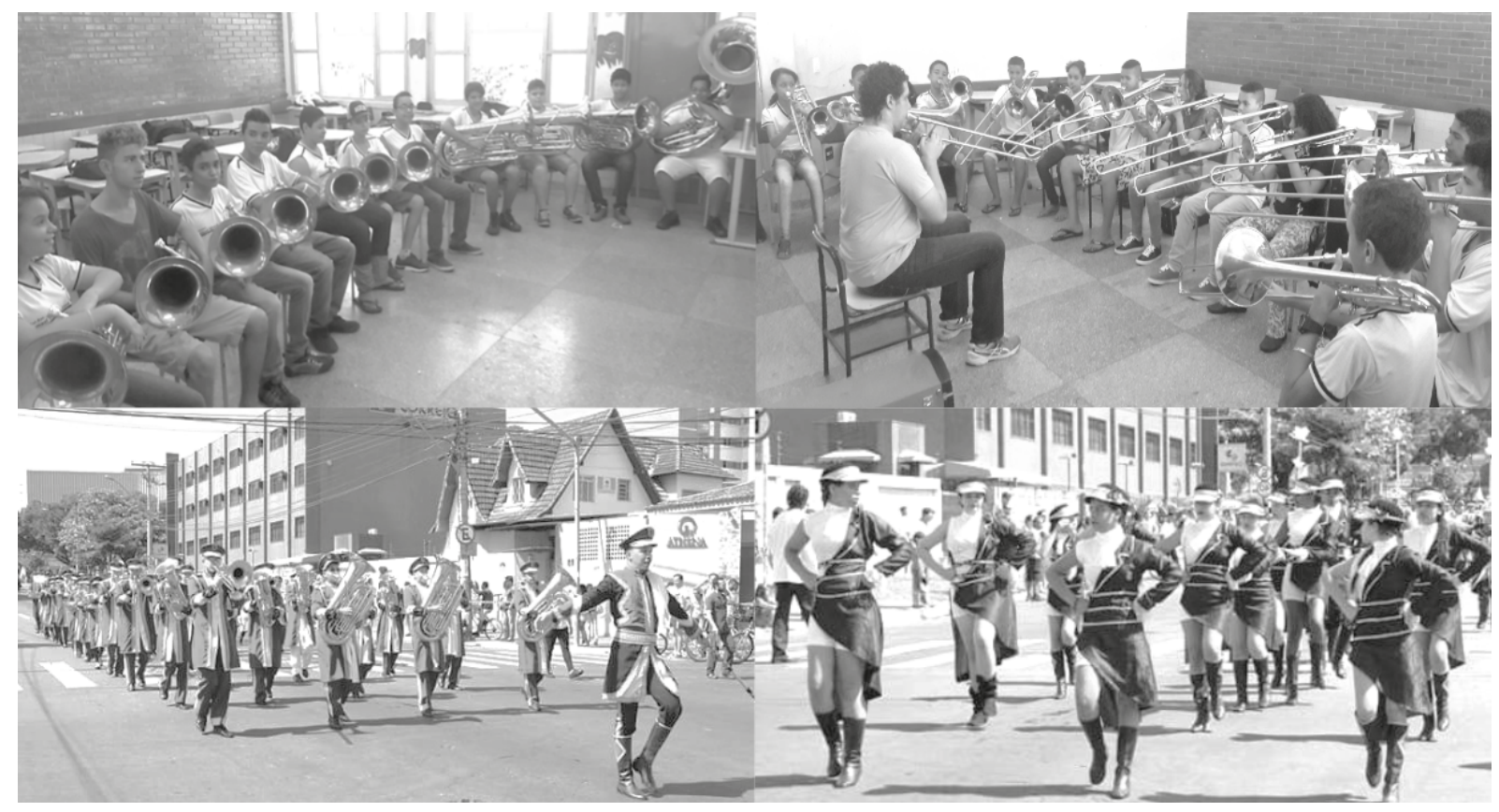

Figura 1: Banda marcial escolar do Cepi Ismael Silva de Jesus. Fonte: arquivo pedagógico. 


\section{ANÁLISE E RESULTADOS}

A análise dos dados da pesquisa survey ${ }^{5}$ tem por comparação a pesquisa de observação e os referenciais teóricos aqui apresentados sobre educação integral, educação de tempo integral, escolas de tempo integral, entre outros.

Como é possivel observar na Figura 2, apresentada a seguir, os estudantes que participaram da pesquisa possuem, na maioria dos casos, de 11 a 14 anos de idade, sendo que $55,6 \%$ dos alunos são do sexo masculino, o que está de acordo com a faixa etária dos estudantes do $6^{\circ}$ ao $9^{\circ}$ ano do ensino fundamental, como demonstrado na Figura 3, apresentada logo em seguida.
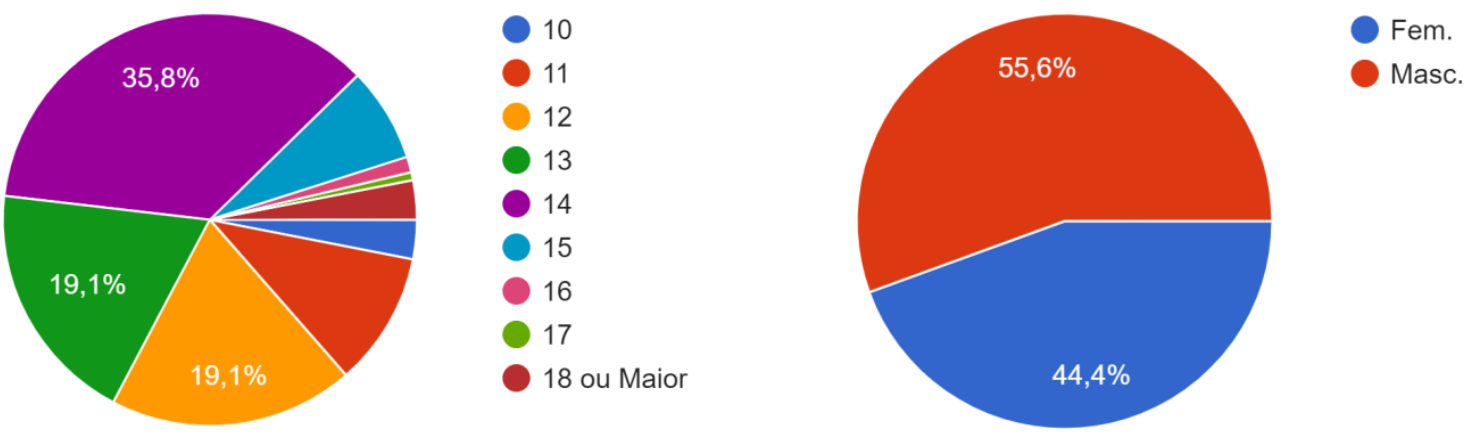

Figura 2: Idade e gênero dos estudantes respondentes.

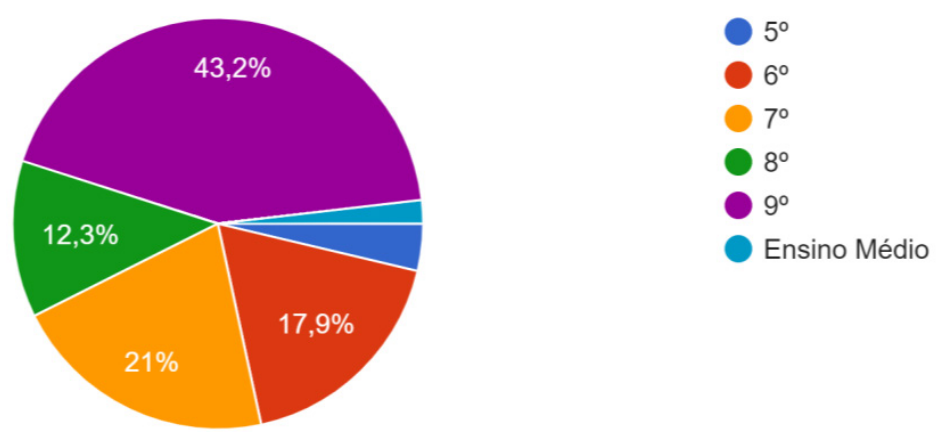

Figura 3: Ano escolar que o estudante está cursando.

Além dessa identificação sobre o estudante nos pareceu importante confirmar o status socioeconômico desse público, por meio da escolaridade do pai e da mãe, ${ }^{6}$ os quais podem ser acessados na Figura 4, a seguir.

\footnotetext{
5 A aplicação do questionário contou com a colaboração dos pibidianos participantes das eletivas da escola (Coelho; Sousa; Pereira; Silva Sá, 2019; Sousa, 2019).

6 Não apresentamos aqui, mas também identificamos o bairro onde moram e a profissão dos pais.
} 
Escolaridade da mãe

162 respostas

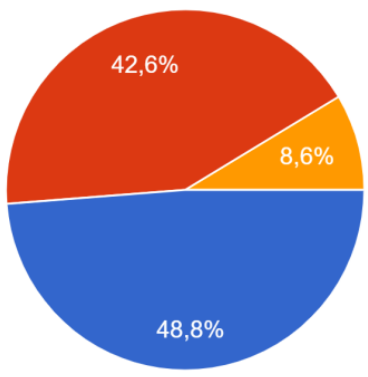

Escolaridade do pai

162 respostas

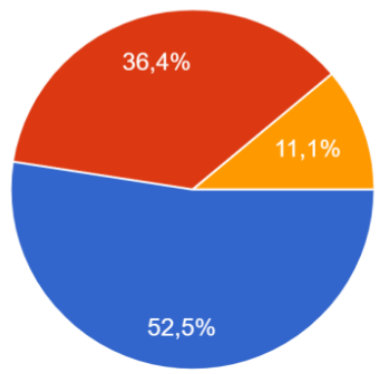

Fundamental

Ensino médio

Superior

Figura 4: Identificação da escolaridade dos pais.

Na Figura 5, apresentada a seguir, identificamos há quanto tempo os estudantes pesquisados possuem aulas de música na escola. Esse dado é importante para revelar o tempo de contato dos estudantes com a música no ensino formal, revelando que mais $60 \%$ dos estudantes já tinham aulas de música anteriormente, e apenas $38,3 \%$ dos estudantes estavam tendo um contato recente com esse conteúdo.

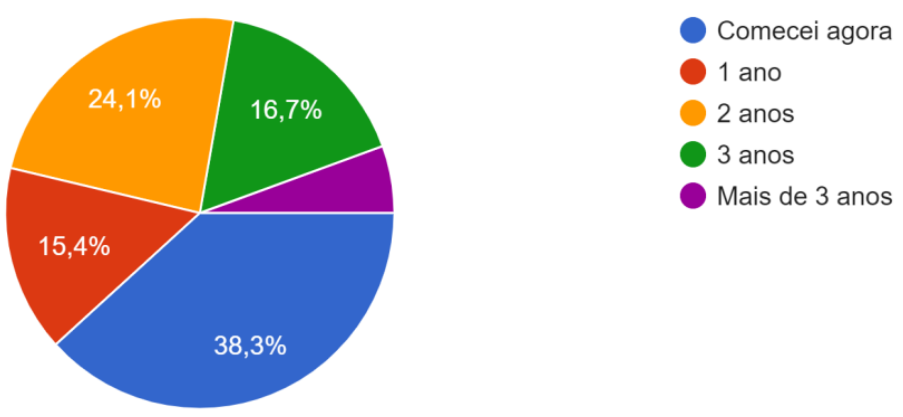

Figura 5: Tempo de acesso ao conteúdo musical na escola.

Procuramos nos aprofundar sobre a relação dos estudantes com a música, questionando se eles separavam um momento para apreciação musical, ao que a grande maioria respondeu que sim, majoritariamente diariamente ou semanalmente, conforme a Figura 6, a seguir.

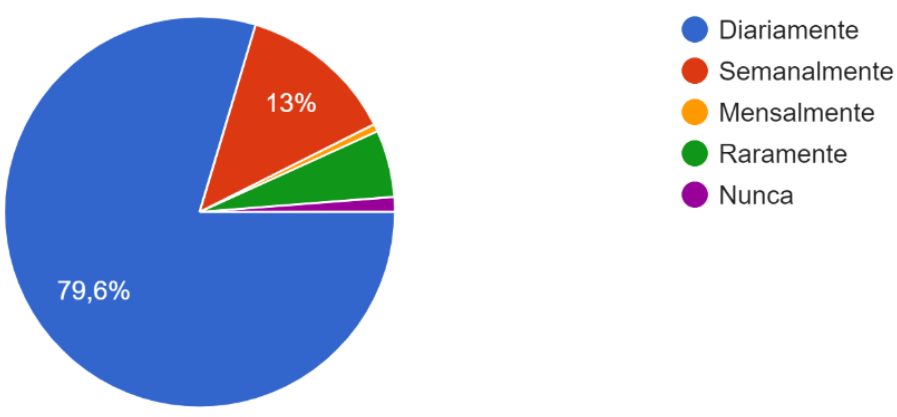

Figura 6: Se costuma separar momentos para ouvir música. 
Ainda, procurando nos aprofundar no acesso e relação com a música desse público, identificamos, na Figura 7 a seguir, que a maioria ouve música por streaming (internet), usando também o celular, computador, pen drives e players digitais portáteis.

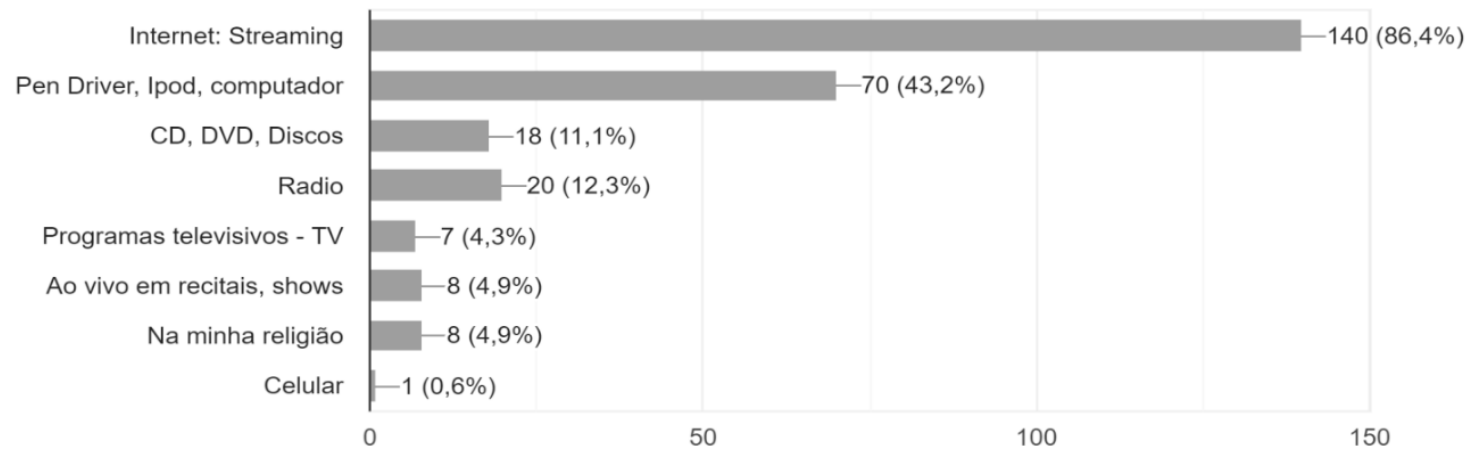

Figura 7: Quais os meios usados para ouvir música.

Por fim, no contexto de identificar o acesso e contato dos estudantes com a música em suas formas de apreciação, ainda perguntamos com quais gêneros ou estilos musicais os estudantes mais se identificavam ou quais aqueles que mais ouviam, sendo que a grande maioria respondeu funk, sertanejo, rap, pop, rock, punk e gospel, o que está explícito na Figura 8 a seguir.

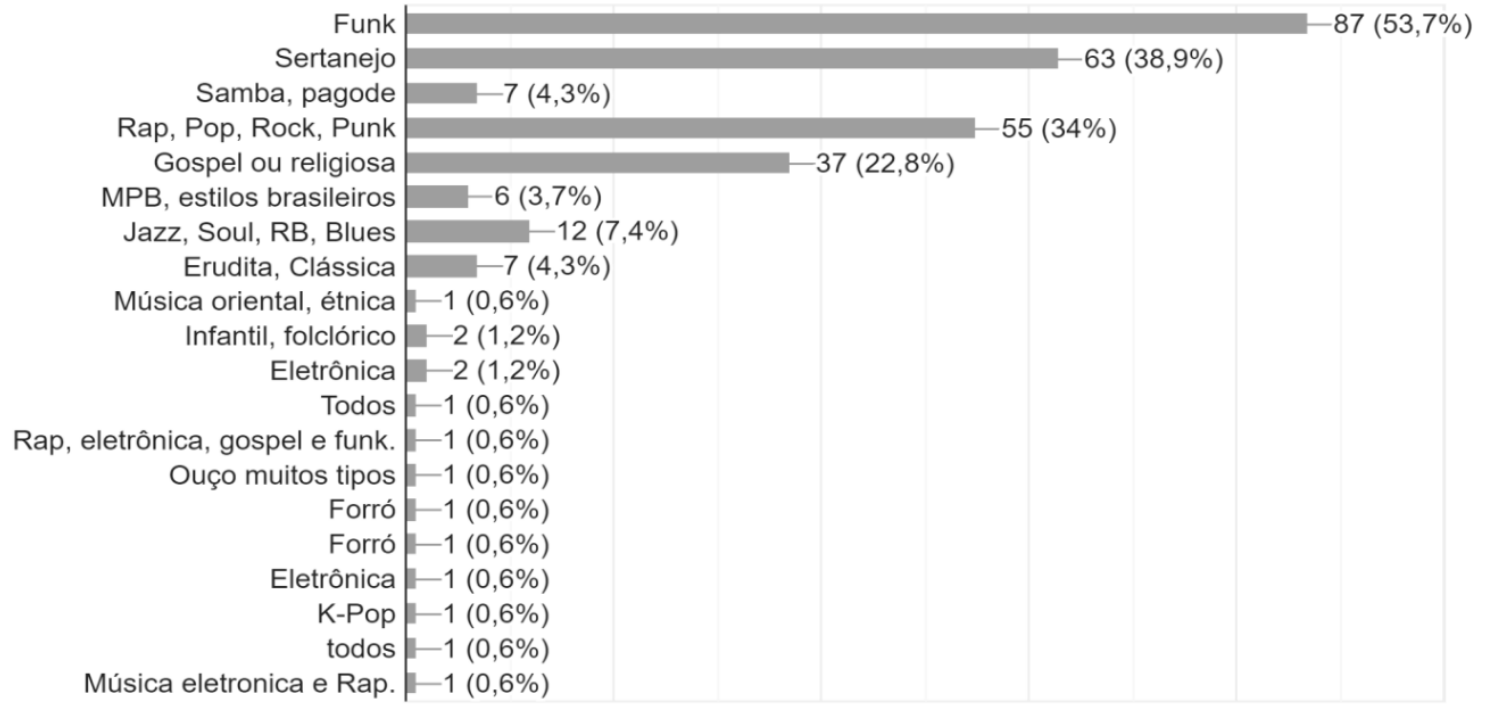

Figura 8: Gêneros ou estilos musicais mais ouvidos pelos estudantes.

Ainda buscamos identificar as relações dos estudantes com a música no contexto da escola de tempo integral. Como existem diversas possibilidades de disciplinas e projetos nesse contexto, questionamos em quais deles os estudantes participam, o que pode ser verificado na Figura 9 a seguir. 


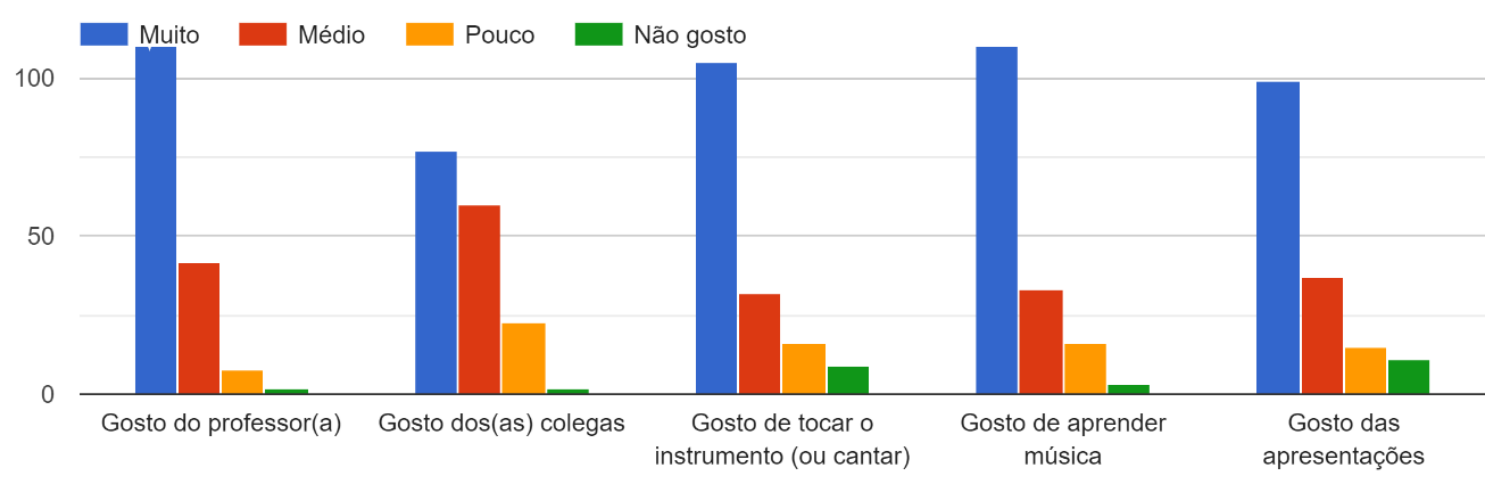

Figura 9: Como é vivenciada a música na escola de tempo integral.

Na Figura 10 a seguir, apresentamos as respostas dos estudantes sobre o seu nível de satisfação com as aulas de música no contexto da escola de tempo integral. Em sua maioria os estudantes apresentaram respostas positivas sobre essa questão.

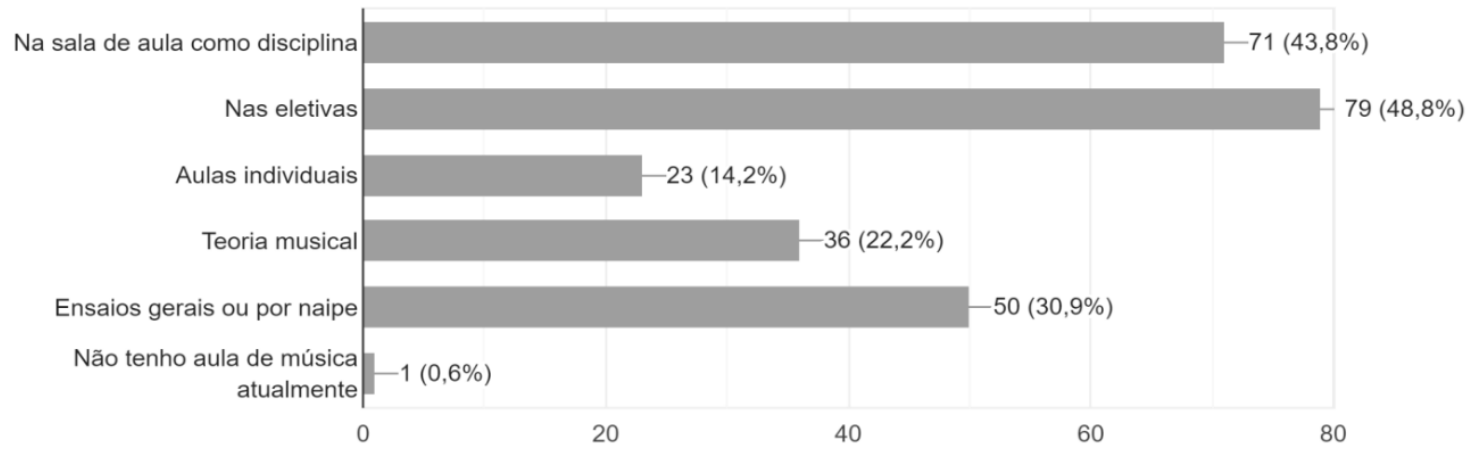

Figura 10: Nivel de satisfação com as aulas de música na escola de tempo integral.

Na Figura 11 a seguir, apresentamos as respostas dos estudantes sobre possiveis contribuições das aulas de música para suas vidas; as respostas mais significativas apontam para a opinião de que a música os faz sentirem-se bem consigo mesmos e para a opinião de que a música traz alegria e prazer.

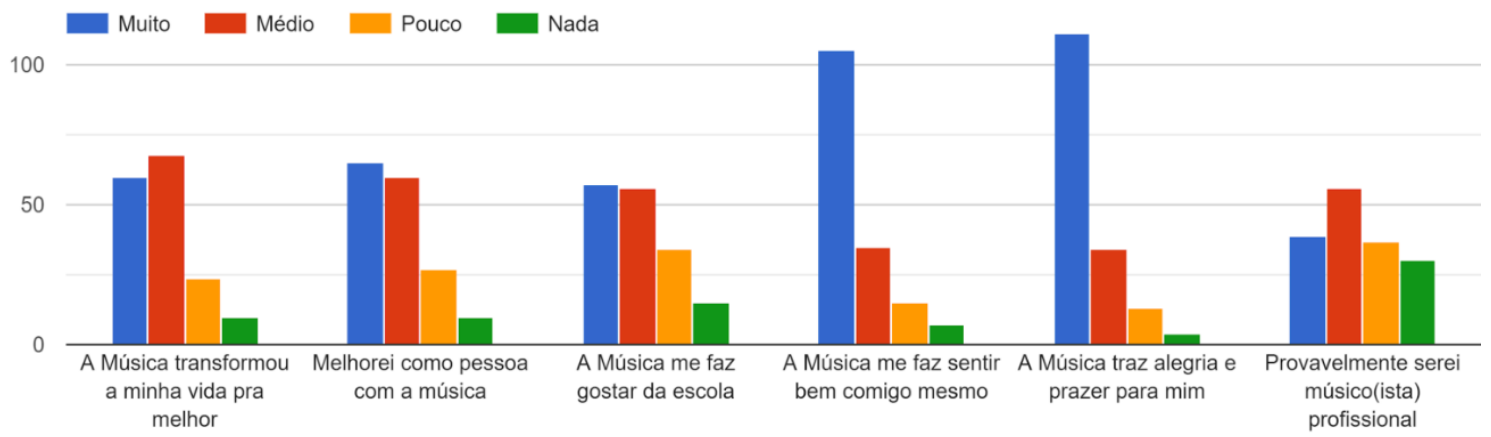

Figura 11: Contribuições das aulas de música para as vidas dos estudantes. 
Identificamos que $61 \%$ dos estudantes vivenciam música fora da escola também, o que pode ser um dado interessante para esta pesquisa, e que pode ser observado na Figura 12, apresentada a seguir.

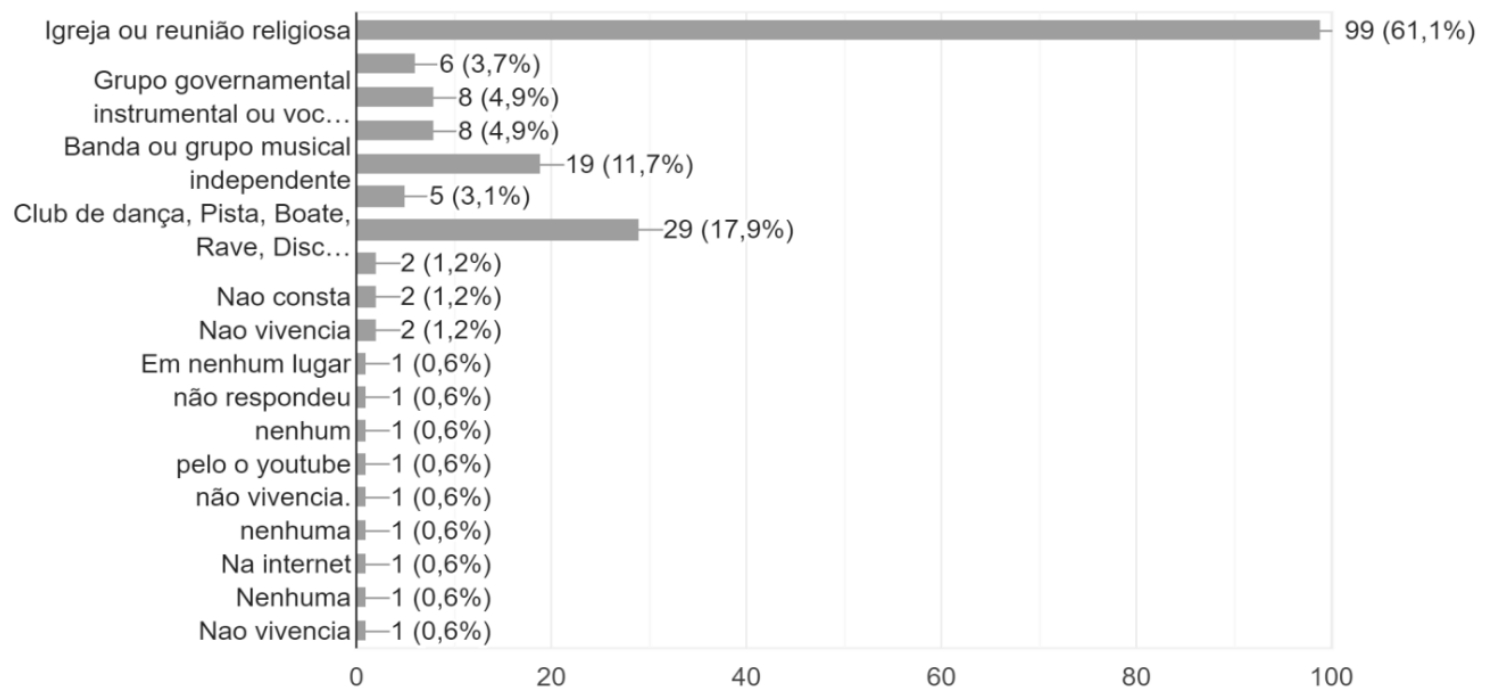

Figura 12: Como o estudante vivencia música fora da escola.

\section{CONCLUSÃO}

Consideramos que a temática da presença da educação musical no contexto das escolas de tempo integral ainda está em aberto na pesquisa educacional e musical no Brasil. Concordamos com Penna (2011), Veber (2012), Souza (2015) e Sousa (2017) quando esses autores ligam a educação integral à ampliação do tempo do estudante na escola, ou seja, a escola de tempo integral possui uma tendência a possibilitar a educação integral, mas temos a consciência de que são necessários contínuos esforços para que a integralização não seja somente na questão do tempo, mas também, e principalmente, na formação plena dos estudantes.

Dando continuidade a estudos semelhantes já desenvolvidos, como por exemplo por Penna (2011), Veber (2012), Souza (2015), Sousa (2017) e Sousa e Soares (2018), e em Goiás por Lourenço (2015) e Ramos (2012), os processos pedagógicos envolvendo a educação musical nas escolas de tempo integral têm sido uma preocupação dos docentes envolvidos; assim, várias ações e estudos têm sido feitos e estão em andamento sobre essa nova realidade.

Nossa pesquisa revelou que o público atendido na escola pesquisada, que aqui é representativa da região periférica da capital, mas também representativa da região metropolitana como um todo, é composto por crianças e adolescentes pertencentes a famílias com baixo poder aquisitivo e baixa escolaridade. Outro dado importante é que a maioria dos estudantes, apesar dessa realidade socioeconômica, vivencia a música no seu dia a dia, seja 
por meio da internet, por meio de outras mídias de comunicação popular, ou ainda no contexto religioso, sendo que as músicas ouvidas por eles são, em sua maioria, o funk, o sertanejo e o rock, que são estilos muito divulgados pelas mídias na atualidade. Nesta pesquisa, também constatamos que existe uma forte ligação dos estudantes com as aulas de música, havendo um forte elemento subjetivo, um sentimento de atração deles pela música, e nesse contexto aparecem as disciplinas de sala de aula, as disciplinas eletivas e ensaios dos grupos musicais, que contam com a aprovação efetiva da maioria dos estudantes.

Nossa experiência junto a escolas de tempo integral confirma que esse modelo de escola tem sido benéfico para as ações de educação musical, não só pela ampliação de espaço, pela efetivação de uma carga horária configurada como disciplina (e não como um projeto à parte, como em muitas outras realidades), mas também como um processo que apresenta marcas de sucesso pedagógico e sociocultural. O que temos vivenciado é que essa experiência tem sido positivamente formativa para os estudantes envolvidos.

Especialmente para a banda marcial da unidade escolar Cepi Ismael Silva de Jesus, essa ampliação de espaço e a inserção dos horários da banda nos horários das aulas (no decorrer da semana) trouxeram um direcionamento diferenciado para o projeto, que no caso é um projeto histórico da unidade escolar, como igualmente em milhares de escolas públicas espalhadas pelo Brasil.

Fazemos aqui uma defesa da necessidade da manutenção das disciplinas eletivas e de sua relevância nas escolas de tempo integral, principalmente das disciplinas ligadas às artes e à música. Salientamos que as eletivas têm se configurado, inclusive, como espaço de trabalho da linguagem específica da música, na prática instrumental ou canto, o que já era feito pelas bandas, mas que se amplia para vários instrumentos musicais e formações de novos conjuntos.

O nosso estudo aponta para a necessidade da ampliação de pesquisas sobre as várias experiências educativas musicais que são desenvolvidas no contexto da escola pública de educação básica no Brasil.

\section{REFERENCIAS}

ARROYO, Miguel Gonzales. O direito ao tempo de escola. Cadernos de Pesquisa, São Paulo, n. 65, p. 3-10, 1988.

BABBIE, Earl. Métodos de pesquisas de survey. Belo Horizonte: Editora UFMG, 2013.

BERNADO, Elisangela da S. Educação em tempo integral: alguns desafios para a gestão escolar. Revista Ibero-Americana de Estudos em Educação, Araraquara, v. 15, n. 1, p. 79-94, 2020. 
BERNADO, Elizangela da S.; CHRISTOVÃO, Ana C. Gestão democrática e educação e $(\mathrm{m})$ tempo integral: o programa mais educação e a Rede Municipal de ensino do Rio de Janeiro. In: CONGRESSO NACIONAL DE EDUCAÇÃO EDUCERE, 12., 2015, Curitiba. Anais [...]. Curitiba: PUCPR, 2015. v. 1, p. 32258-32276.

BRASIL. Constituição da República Federativa do Brasil de 1988. Brasília, DF: Presidência da República, Casa Civil, Subchefia para Assuntos Jurídicos, 1988. Disponivel em: http://www.planalto.gov.br/ccivil_03/ constituicao/constituicao.htm. Acesso em: 26 ago. 2020.

Lei $n^{\circ}$ 8.069, de 13 de julho de 1990. Dispõe sobre o Estatuto da Criança e do Adolescente e dá outras providências. Brasília, DF: Presidência da República, Casa Civil, Subchefia para Assuntos Jurídicos, 1990. Disponivel em: https://www.planalto.gov.br/ccivil_03/leis/18069.htm. Acesso em: 26 ago. 2020.

. Lei $n^{\circ}$ 9.394, de 20 de dezembro de 1996. Estabelece as diretrizes e bases da educação nacional. Brasília, DF: Presidência da República, Casa Civil, Subchefia para Assuntos Jurídicos, 1996. Disponivel em: https:// www.planalto.gov.br/ccivil_03/Leis/L9394.htm. Acesso em: 26 ago. 2020.

. Lei $n^{\circ}$ 10.172, de 9 de janeiro de 2001. Aprova Plano Nacional de Educação e dá outras providências. Brasília, DF: Presidência da República, Casa Civil, Subchefia para Assuntos Jurídicos, 2001. Disponivel em: http:/ /www. planalto.gov.br/ccivil_03/leis/leis_2001/110172.htm. Acesso em: 26 ago. 2020.

- Ministério da Educação. Plano de desenvolvimento da educação: razão, princípios e programas. Brasília, DF: MEC, 2007a. Disponível em: http:/ /www.dominiopublico.gov.br/download/texto/me004370.pdf. Acesso em: 26 ago. 2020.

Lei $n^{\circ} 11.494$, de 20 de junho de 2007. Regulamenta o Fundo de Manutenção e Desenvolvimento da Educação Básica e de Valorização dos Profissionais da Educação - FUNDEB, de que trata o art. 60 do Ato das Disposições Constitucionais Transitórias; altera a Lei $\mathrm{n}^{\circ} 10.195$, de 14 de fevereiro de 2001; revoga dispositivos das Leis $\mathrm{n}^{\circ} 9.424$, de 24 de dezembro de 1996, 10.880, de 9 de junho de 2004, e 10.845, de 5 de março de 2004; e dá outras providências. Brasília, DF: Presidência da República, Casa Civil, Subchefia para Assuntos Jurídicos, 2007b. Disponível em: http:/ /www. planalto.gov.br/ccivil_03/_ato2007-2010/2007/lei/111494.htm. Acesso em: 26 ago. 2020.

Ministério da Educação. Conselho Nacional de Educação. Câmara de Educação Básica. Resolução n 4, de 13 de julho de 2010. Define as Diretrizes Curriculares Nacionais Gerais para a Educação Básica. Diário Oficial da União: seção 1, Brasília, DF, p. 824, 14 jul. 2010. Disponível em: http:// portal.mec.gov.br/dmdocuments/rceb004_10.pdf. Acesso em: 26 ago. 2020. 
BRASIL. Ministério da Educação. Secretaria de Articulação com os Sistemas de Ensino Planejando a próxima década: conhecendo as 20 metas do Plano Nacional de Educação. Brasília, DF: MEC/SASE, 2014. Disponivel em: http://pne.mec.gov.br/images/pdf/pne_conhecendo_20_metas.pdf. Acesso em: 26 ago. 2020.

CAVALIERE, Ana Maria. Tempo de escola e qualidade na educação pública. Educação \& Sociedade, Campinas, v. 28, n. 100, p.1015-1035, 2007. DOI: 10.1590/S0101-73302007000300018.

. Escolas de tempo integral versus alunos em tempo integral. Em Aberto, Brasília, DF, v. 21, p. 51-63, 2009.

Escola pública de tempo integral no Brasil: filantropia ou política de Estado?. Educação \& Sociedade, Campinas, v. 35, n. 129, p. 1205-1222, 2014.

COELHO, Ângela C.; SOUSA, Aurélio N. de; PEREIRA, Eliton P. R.; SILVA SÁ, Fábio A. da. Pibid Música IFG: iniciação à docência em 2018 e 2019. In: CONGRESSO DA ASSOCIAÇÃO BRASILEIRA DE EDUCAÇÃO MUSICAL, 24., Campo Grande. Anais [...]. Campo Grande: Abem, 2019. Sem paginação.

COELHO, Lígia M. C. da C. História(s) da educação integral. Em Aberto, Brasília, DF, v. 22, p. 83-96, 2009.

DEL-BEN, Luciana M. Modos de pensar a educação musical escolar: uma análise de artigos da Revista da Abem. InterMeio, Santa Maria, v. 37, n. 19, p. 125-148, 2013.

FREITAS, Henrique; OLIVEIRA, Mirian; SACCOL, Amarolinda Z.; MOSCAROLA, Jean. O método de pesquisa survey. Revista de Administração, São Paulo, v. 35, n. 3, p. 105-112, jul./set. 2000.

GOIÁS. Secretaria de Estado da Educação. Escolas de tempo integral. Goiânia: Seduc, [2020]. Disponivel em: https://site.educacao.go.gov.br/ escolas-de-tempo-integral/. Acesso em: 26 ago. 2020.

LOUREIRO, Alícia M. A. O ensino de música na escola fundamental. Campinas: Papirus, 2003.

LOURENÇO, Gilmar dos S. Educação musical na escola de tempo integral: processos pedagógicos em escola estadual de Goiânia-GO. 2015. Dissertação (Mestrado em Música) - Escola de Música e Artes Cênicas, Universidade Federal de Goiás, Goiânia, 2015.

MOLL, Jaqueline; LECLERC, Gesuína F. E. Diversidade e tempo integral: a garantia dos direitos sociais. Retratos da Escola, Brasília, DF, v. 7, n. 13, p. 291-304, 2013. Disponivel em: http://retratosdaescola.emnuvens.com. br/rde/article/viewFile/306/476. Acesso em: 26 ago. 2020. 
PENNA, Maura. Educação musical e educação integral: a música no Programa Mais Educação. Revista da Abem, Londrina, v. 19, n. 25, p. 141-152, abr. 2011. Disponivel em: http://www.abemeducacaomusical.com.br/revistas/ revistaABEM/index.php/revistaabem/article/view/197. Acesso em: 26 ago. 2020.

PIRES, Nair; DALBEN, Ângela I. L. de F. Música nas escolas de educação básica: a produção acadêmica dos cursos de Pós-Graduação Stricto Sensu no Brasil (1972-2011). Opus, [s. l.], v. 19, n. 2, p. 171-208, 2013.

RAMOS, Maria da Luz S. Escola de tempo integral na rede estadual de ensino de Goiás: escola do conhecimento ou do acolhimento?. 2012. Tese (Doutorado em Ciências Humanas) - Pontifícia Universidade Católica de Goiás, Goiânia, 2012.

SOUSA, Aurélio N. Bandas marciais: ensino coletivo nas escolas de tempo integral da cidade de Goiânia-Goiás-Brasil. In: INTERNATIONAL CONFERENCE MUSIC FOR AND BY CHILDREN, 1., Aveiro, Portugal, 2017. Proceedings [...]. Aveiro: UA Editora, 2018. p. 18-25. Disponivel em: https://proa.ua.pt/index. php/musichildren/article/view/1024/832. Acesso em: 26 ago. 2020.

. Pibid Música no Centro de Período de Tempo Integral 'Ismael Silva de Jesus' - Goiânia. In: CONGRESSO DA ASSOCIAÇÃO BRASILEIRA DE EDUCAÇÃO MUSICAL, 24., Campo Grande. Anais [...]. Campo Grande: Abem, 2019. Sem paginação.

SOUSA, Aurélio N.; SOARES, Maíry A. P. O quinhão da banda marcial na formação dos alunos do CEPI-Ismael Silva de Jesus. Fragmentos de Cultura, Goiânia, v. 28, n. 4, p. 492-503, out./dez. 2018. Disponivel em: http://seer.pucgoias.edu.br/ index.php/fragmentos/article/view/6891. Acesso em: Acesso em: 26 ago. 2020.

SOUZA, Ana Maria de C. Articulações pedagógicas em música na formação integral: um estudo de caso na escola de tempo integral na região metropolitana de Belém, Estado do Pará. 2015. Tese (Doutorado em Música) Escola de Música, Universidade Federal da Bahia, Salvador, 2015. Disponível em: https://repositorio.ufba.br/ri/handle/ri/21597. Acesso em: 26 ago. 2020.

VEBER, Andreia. A escola de tempo integral: um espaço potencial para as aulas de música na educação básica. Revista da Abem, Londrina, v. 20, n. 29, p. 39-50, jul./dez. 2012. Disponivel em: http://www. abemeducacaomusical.com.br/revistas/revistaabem/index.php/ revistaabem/article/view/89. Acesso em: 26 ago. 2020.

VIANNA, Heraldo M. Pesquisa em educação: a observação. Brasillia, DF: Plano Editora, 2003. (Série Pesquisa, n. 5).

WALTER, Olga Maria F. C. Análise de ferramentas gratuitas para condução de survey online. Produto \& Produção, Porto Alegre, v. 14, n. 2, p. 44-58, jun. 2013. DOI: 10.22456/1983-8026.22172. 
Aurélio Nogueira de Sousa possui graduação em Educação Musical Ensino Musical Escolar pela Universidade Federal de Goiás (UFG) e especialização em Gestão Escolar pela Faculdade Tecnológica Darwin. É mestre em Música pelo Programa de Pós-Graduação em Música da UFG, sob a orientação da Dra Sônia Ray na linha de pesquisa Educação Musical e Pedagogia da Performance, e doutor em Educação Musical pela Universidade Federal da Bahia (UFBA), com o Dr. Joel Barbosa, com período sanduíche na Universidade de Aveiro, em Portugal, sob a orientação da Dra. Maria do Rosário Pestana. Exerceu o cargo de coordenador do Ponto de Cultura Tocando Arte do programa Cultura Viva do Ministério da Cultura (MinC) entre 2011 e 2015. É professor efetivo de música da Secretaria de Estado da Educação de Goiás, onde exerce o cargo de regente de banda marcial no Centro de Educação de Período em Tempo Integral Ismael Silva de Jesus. Tem experiência na área de artes, com ênfase principalmente nos seguintes temas: educação musical, educação básica, ensino coletivo de banda, regência de bandas de música escolar, ensino de trompete, musicalização infantil, arte-educação, gestão e produção cultural. https://orcid.org/0000-0002-5215-6619

Eliton Perpetuo Rosa Pereira é doutor em Educação pela Universidade de Santiago de Compostela (USC), na Espanha. Licenciado e mestre em Música pela Escola de Música e Artes Cênicas da Universidade Federal de Goiás (EMAC-UFG). Especialista em Tecnologias em Educação pela Pontifícia Universidade Católica do Rio de Janeiro (PUC-RJ). No Instituto de Educação, Ciência e Tecnologia de Goiás (IFG) atua na Licenciatura em Música e no Mestrado Prof-Artes. Tem experiência em educação musical, canto coral, metodologia científica e formação de professores. https://orcid.org/0000-0002-9181-2543 